\title{
NOTICIAS SOBRE ARQUITECTURA COLONIAL
}

\author{
P O R \\ FRA NCISCO DE LA MAZA
}

Las Casas Reales de Guanajuato en 1792

$\mathrm{E}^{\mathrm{N}}$ el tomo 31 del fecundo Ramo de Obras Públicas, del Archivo E General de la Nación, hay un legajo que se titula : "Expediente en que se instruye el costo que demanda la reforma o composición de las Casas Reales de esta Ciudad de Guanaxuato, Capital de Provincia, y la necesidad y utilidad de esta obra, probada por la información recibida de tres testigos contestes y de toda excepción." En efecto, los testigos don Agustín Pérez Marañón, don Bernabé de Bustamante y don Martín de la Riva, declararon que "con motivo de hallarse las Casas Consistoriales o Capitulares de esta Ciudad en el más deplorable ruinoso estado por su antigüedad e inferior condición de su fábrica, necesita de continuos, anuales reparos que ocasionan un cuantioso gasto con perjuicio de los caudales de Propios, sin que por esto se haya conseguido proporcionar una habitación cómoda y decente para el alojamiento del Jefe de la Provincia, ni para las funciones que en ella se celebran ni para el decoro de las que corresponden a este Ayuntamiento". Pidieron un "reparo radical", por lo cual, reunido el cabildo municipal el 28 de octubre de 1792, acordó que "visto el estado indecente de estas Casas Reales y la ninguna comodidad que ofrecen para ser habitadas", se comisionase al regidor don Juan Vicente Alamán para el examen del edificio y su reparación, y mientras tanto pasase el Intendente, que lo era don Juan Antonio Riaño, a vivir a una buena casa cuya renta pagaría la ciudad. Añadió el Ayun- 
tamiento que "viendo como es esta ciudad una de las más principales del Reino por su populoso vecindario, por la opulencia de sus minas y por ser en el día capital de una de sus mayores provincias, es una cosa muy notable e indecorosa el que sus Casas Capitulares se hallen en un estado tan ruinoso, incómodo y tan poco habitable, que ni aun para un sujeto particular de una mediana distinción sería indecente y más cuando los edificios públicos deben dar una idea de la importancia de las poblaciones". Esta última frase parece que se escribió para las actuales autoridades de Guanajuato, que afean a la ciudad a base de falsas grandezas arquitectónicas. Firman el acuerdo don Juan Antonio Riaño, Martin Pérez Maranón, Vicente Rexil, Martín Coronel y José Septién. Fueron nombrados para la reconstrucción del edificio, el maestro albañil Juan de Dios Trinidad Pérez, el maestro herrero Juan Luis Guzmán y el maestro carpintero José Victoriano Rodríguez, los cuales llegaron a la conclusión de que costaría la reparación 13,748 pesos en cuanto a la obra de arquitectura; 3,813 la de herrería y 1,632 la de carpinteria.

Se envió la documentación a México para solicitar el permiso virreinal, pero el cauto Conde de Revillagigedo contestó que "el asunto no venía instruído en forma bastante pues debia haberse empezado por un reconocimiento de peritos que diese mayor idea del actual estado, antigüedad, materiales, situación y capacidad de las Casas Reales que se intentan reparar", en enero de 1793. También preguntó si había el dinero suficiente en la Real Caja.

Riaño contestó de inmediato que "el Ayuntamiento devuelve a las superiores manos de V. E. diligenciado el despacho que se sirvió librarle, y espera que la acreditada justificación y celo de V. E. se digne concederle el permiso que tiene pedido con cuanta brevedad sea posible". Al devolver la documentación iban los peritajes pedidos por Revillagigedo, hechos por el arquitecto don José Alejandro Durán y Villaseñor (que después sería director de la famosa Alhóndiga de Granaditas siguiendo los planos enviados de México, hechos por el arquitecto don José del Mazo y Avilés) y el maestro albañil José Guadalupe Rivera, que andaba en ese tiempo encargado de hacer las garitas de la ciudad, quienes estuvieron de acuerdo con los planos de Trinidad Pérez. El Contador don Francisco Mariño contestó, a su vez, que había hasta 10,000 pesos más de lo que se pedía. Visto por el virrey, se concedió el permiso el 7 de mayo, por lo que comenzaron Pérez y Rivera la reconstrucción, encontrándose la sorpresa de que el edificio antiguo no tenía cimientos, que estaba "a pelo 
de tierra", por lo que se necesitaban, de menos 2,000 pesos más, por lo cual vuelven a pedir permiso nuevo, incluyéndose entre las firmas la del Conde de Valenciana. Aquí termina el expediente, por lo que no sabemos más del asunto, aunque nos quedan los dibujos de Trinidad Pérez, que es lo más importante para nosotros.

No sabemos hasta que punto el alzado de Pérez conserva el antiguo edificio de las Casas Reales, pero parece que nada, ya que su proyecto está inspirado en las ideas neoclásicas y las Casas Reales anteriores eran muy antiguas, es decir, barrocas.

Ocupa el proyecto el mismo lugar que el actual Palacio de Gobierno, al comienzo de la subida de la Cuesta del Marqués, en la esquina del callejón de la Condesa, por lo que lleva el desnivel que se nota desde las pilastras hacia arriba. El frente lo forman tres puertas adinteladas, con adornos de triglifos y metopas, tres balcones con parteluz en el segundo piso y cinco sin parteluz en el tercero. El friso lleva también sus clásicos elementos y sobre él la balaustrada corrida, con macetones rematando las pilastras adosadas que separan las puertas y balcones. En el centro un espectacular escudo real, que él sólo iba a costar 175 pesos. Una hermosa solución de Trinidad Pérez fue la fachada lateral, en el callejón de la Condesa, creando una arquería que le daba una ligereza y una gracia espléndidas a pesar de los gruesos pilares que la formaban. La escalera iba dignamente coronada por una cúpula redonda, con elevada linternilla y sus bien repartidos gajos. No nada más Tresguerras sabía de arte neoclásico en Guanajuato a fines del siglo xvirr.

El plano está minuciosamente explicado en su distribución interior:

A- Sitio de la Sala principal.

B- Sala Capitular.

C- Recámara primera.

D- Recámara segunda.

E- Cuarto de Tocador.

$\mathrm{F}$ - Antesala.

G- Comedor.

$\mathrm{H}-$ Cuarto de criados.

I- Despensa.

$\mathrm{J}$ - Cocina.

$\mathrm{K}$ - Cuarto de cocineros.

L- Lugares comunes. 
M-- Azotehuela.

N- Escalera a la azotea.

O- Arca de la linternilla de la escalera principal.

$\mathrm{P}$ - Cuarto de maceros.

Q- Patio principal.

No es un modelo de distribución, con el cuarto de criados dando al comedor y el cuarto de la cocinera con tanta amplitud como la "recámara primera", pero si esa fué la idea de Pérez, podía modificarse con facilidad. En cuanto a la enorme lejanía de los "lugares comunes" fué un achaque de toda casa anterior al siglo $\mathbf{x x}$.

¿Se construyó exactamente este edificio colonial guanajuatense de Gobierno? Lo ignoro. Ahora lo sustituye el actual, de este siglo, con aciertos y desaciertos, pero que cumple bien su misión como Palacio de Gobierno del Estado.

Obras en el Palacio de México.

En el mismo tomo 31 del Ramo de Obras Públicas hay dos expedientes sobre reparaciones y obras del Palacio Real de México. El primero es "sobre construcción y fábrica de un corredor en el segundo patio de este Real Palacio y Sala de Despacho para Su Excelencia" fechado en 1761 .

Hizo los planos y diseños el ingeniero don Agustín de la Cámara Alta, y el oidor don Domingo Valcárcel pidió al virrey Marqués de Cruillas que "se proceda desde luego a la práctica de esta obra nombrando maestros para examinar si se perjudica la fábrica principal del $\mathrm{Pa}$ lacio". Fueron nombrados los arquitectos Manuel Alvarez y Joaquín García de Torres, los cuales dijeron que "visto el plano de uno de los lados del segundo patio que es el que mira al oriente, les pareció bien para el despacho de S. E., por carecer ahora de piczas cómodas para ello, siendo estas más sanas por mirar al oriente y gozar de sol en todos tiempos y la construcción de dicho paso es la mejor que puede hacerse en la forma, modo y tamaños que se demuestran, con lo que queda con toda solidez y firmeza sin que en manera alguna perjudique a la fábrica del Palacio". Con estas opiniones en pro, se dió comienzo a la obra de inmediato, llegando las cuentas, hasta enero de 1762 , a 10.850 pesos. 
El ingeniero De la Cámara Alta, que había sustituido a Lorenzo Rodríguez como Arquitecto Mayor del Real Palacio, dió ejemplo de rapidez y pericia extraordinarias. El maestro carpintero encargado de las obras de madera fue Cristóbal Terrazas.

En la planta explica el ingeniero: "por el plano y perspectiva se manifiesta el balconaje y paso exterior que se puede comunicar para la familia de $V$. E. y quedan libres los apartamentos que deben servir para el despacho en tiempo de invierno por ser los que tiene ahora V. E. muy enfermos y no darles el sol, y más abrigado y a mano para dicho despacho siendo los mismos que con dictamen de V. E. se eligieron y se deben reparar". El plano indica el ángulo nororiental del corredor, con sus pilastras y el balcón de madera de cedro que unía las habitaciones. Se dibuja la "péndola y crucero de fierro (que) se mira de perfil". En la perspectiva vemos la parte principal del corredor, con sus arcos libres abajo y cegados arriba para los despachos del virrey, fea solución que hoy se ha corregido y el balcón corrido que ni siquiera llegaba al arco final. Se conserva casi intacta la obra en el hoy Patio de Honor, que sirve todavía de despacho al Presidente de la República, extrañándonos un mucho que en 1761 se edificase una obra tan austera, de vigorosas reminiscencias clásicas, en los momentos en que se terminaba el templo churrigueresco del Sagrario. Ahora el balconaje y las "péndolas" se han sustituido por balaustres y han desaparecido los tabiques que cegaban los arcos $y$ las tres diferentes $y$ horribles puertas que se abrian en ellos.

El segundo expediente trata de la construcción de las garitas que existieron cabe las puertas de Palacio. El 21 de mayo de 1791 pidió el Conde de Revillagigedo como "urgente", se construyesen cinco garitas de madera "para que usen de ellas en los casos prevenidos por la ordenanza los centinelas destinados de mi guardia a custodiar exteriormente este Real Palacio, debiendo construirse con la posible solidez para evitar frecuentes composiciones y estar, además sobre ruedas de bronce a fin de que puedan moverse y trasladarse fácilmente cuando convenga. Pase este decreto al Teniente Coronel de Ingenieros Don Miguel Costanzó".

El diligente Costanzó hizo rápidamente un diseño según "se estilan las garitas en las puertas de los edificios militares", con un costo de 1,060 pesos las cinco, con sus techos a dos aguas y sus tres aspilleras. Pasó el expediente a la Junta Superior de Hacienda, la cual contestó, por voz del Contador don Ramón Gutiérrez del Mazo "he visto que en la superior orden de 21 de mayo se trata de cinco garitas, pero son indis- 
pensablemente necesarias seis, dos para cada puerta y otras dos para los ángulos del Norte y del Sur, una en el baluarte del Volador y otra en la esquina de Provincia, y también que haciéndose de madera serían de menor duración, corruptibles y siempre con la necesidad de componerse con frecuencia y por todo contraté con el maestro Mayor de las obras de este Real Palacio, don Francisco Guerrero y Torres, se construyesen de piedra de chiluca con vuelos y escalones de recinto negro, así para la harmosura de su vista como para su duración, según se percibe del plan que acompaña, delineado por el Teniente Coronel don Miguel Costanzó". Como se ve, el activo Contador no sólo propuso, sino logró otro proyecto de piedra del mismo Costanzó, con la seguridad, por la razón absoluta que le asistía, de que seria aceptada su proposición de las garitas de piedra.

Se encargó de ello Guerrero Torres, pero sin seguir los proyectos originales, pues le pareció que era muy caro lo de los escalones de piedra negra y los puso de chiluca también, además de ciertas torpezas que le criticó Costanzó, pues "yo formulé el proyecto - dice- proponiéndome hacer las garitas ligeras cuanto es dable, porque de otra suerte más sirvieran de estorbo que de ornato, por esta razón sus paredes no tienen más que nueve pulgadas de grueso y este corto espesor exige que las cupulitas sean delgadas y del menor numero de piezas posible pues asi se obvia el empuje general ...., no se hizo cargo de esto, ciertamente, el maestro Francisco Torres cuando cerró el ajuste de las garitas, del que no tuve noticia, pero sino se hace la obra como yo pido se expondrá a verla levantada y arruinada el mesmo día en el que se quitase la cimbria de las bovedillas".

Guerrero y Torres aceptó las condiciones de Costanzó y prometió entregar las garitas terminadas en cuatro meses; sin embargo, un año después, en mayo de 1792 aún no estaban, a pesar de "las quasi diarias y continuas interpelaciones que se le hacian", hasta que por fin, según parece en el incompleto expediente, las terminó a fin de ese año.

Los garitones -o sean las "garitas" de los documentos- las hizo Guerrero y Torres cuatro frente a dos de las puertas de Palacio y dos en las esquinas. Asi duraron hasta 1840, como puede verse en el grabado de Rafael Ximeno de la Plaza Mayor en 1808 y en un dibujo de Pedro Gualdi que publica don Jesús Galindo y Villa en su estudio La Plaza Mayor de México (Anales del Museo Nacional, 1913, tomo v). Por otra litografía, publicada por don José Maria Gutiérrez Estrada se ve que, 
DOI: http://dx.doi.org/10.22201/iie.18703062e.1953.21.553

después del "cuartelazo" de Urrea y Gómez Farías, los garitones quedaron hechos añicos, por lo que hubo que rehacerlos, más o menos imitando el modelo de Costanzó y no repitiéndolos exentos, sino adosados. En la litografia que reproduce Ribera Cambas en su México Pintoresco, de 1880, aparecen ya como están en la actualidad. Al adosarlos se cerraron los tres lados del exágono y se les pusieron aspilleras y el remate de la bola no descansa sobre el clásico dado, sino directamente sobre el cupulin.

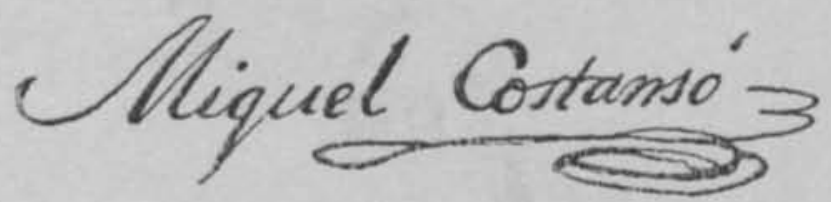

(Firma de Costanzó en los expedientes citados). 
DOI: http://dx.doi.org/10.22201/iie.18703062e.1953.21.553 
DOI: http://dx.doi.org/10.22201/iie.18703062e.1953.21.553

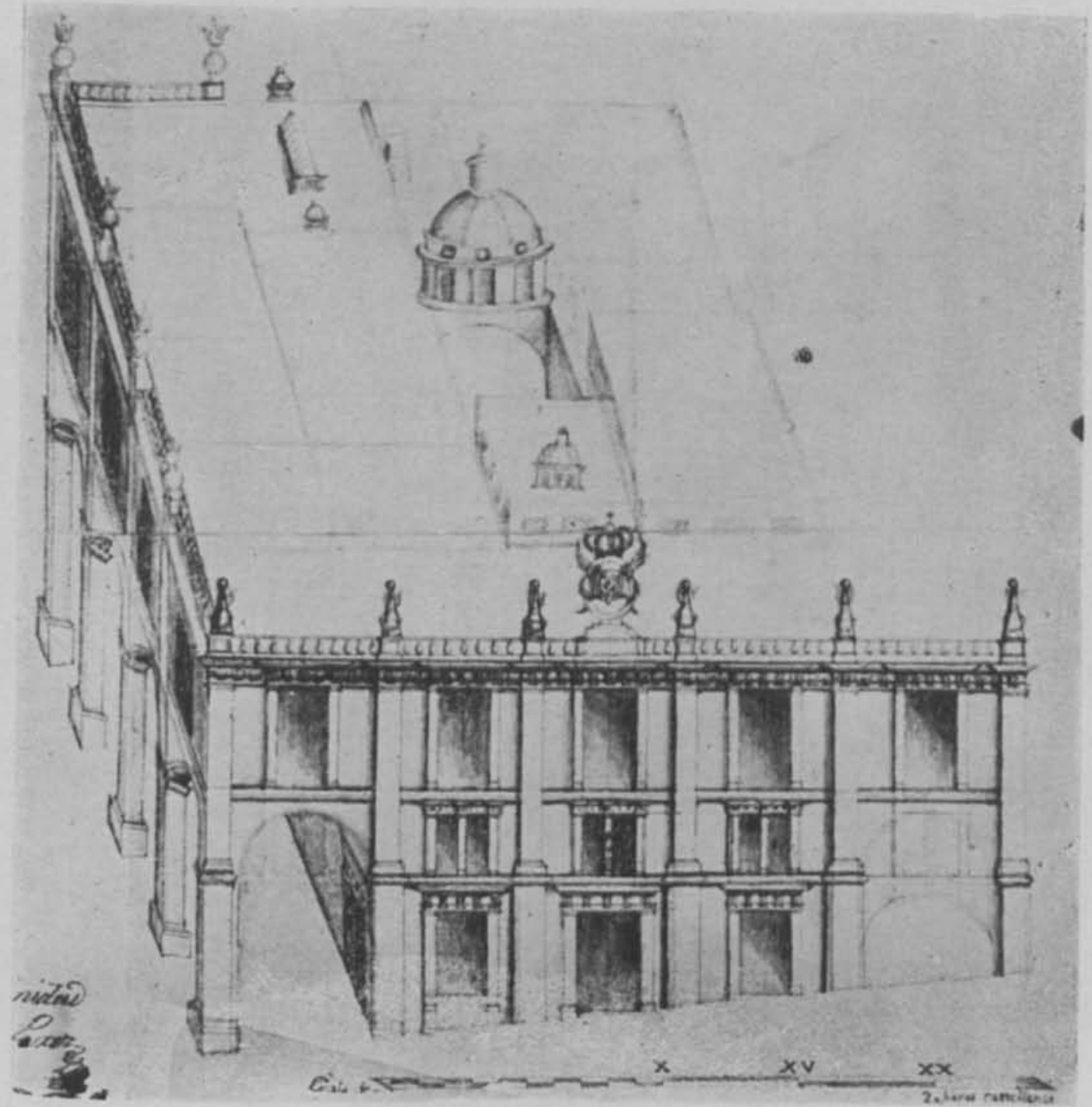

1. Alzado de las Casas Reales de Guanajuato. 1792. 
DOI: http://dx.doi.org/10.22201/iie.18703062e.1953.21.553

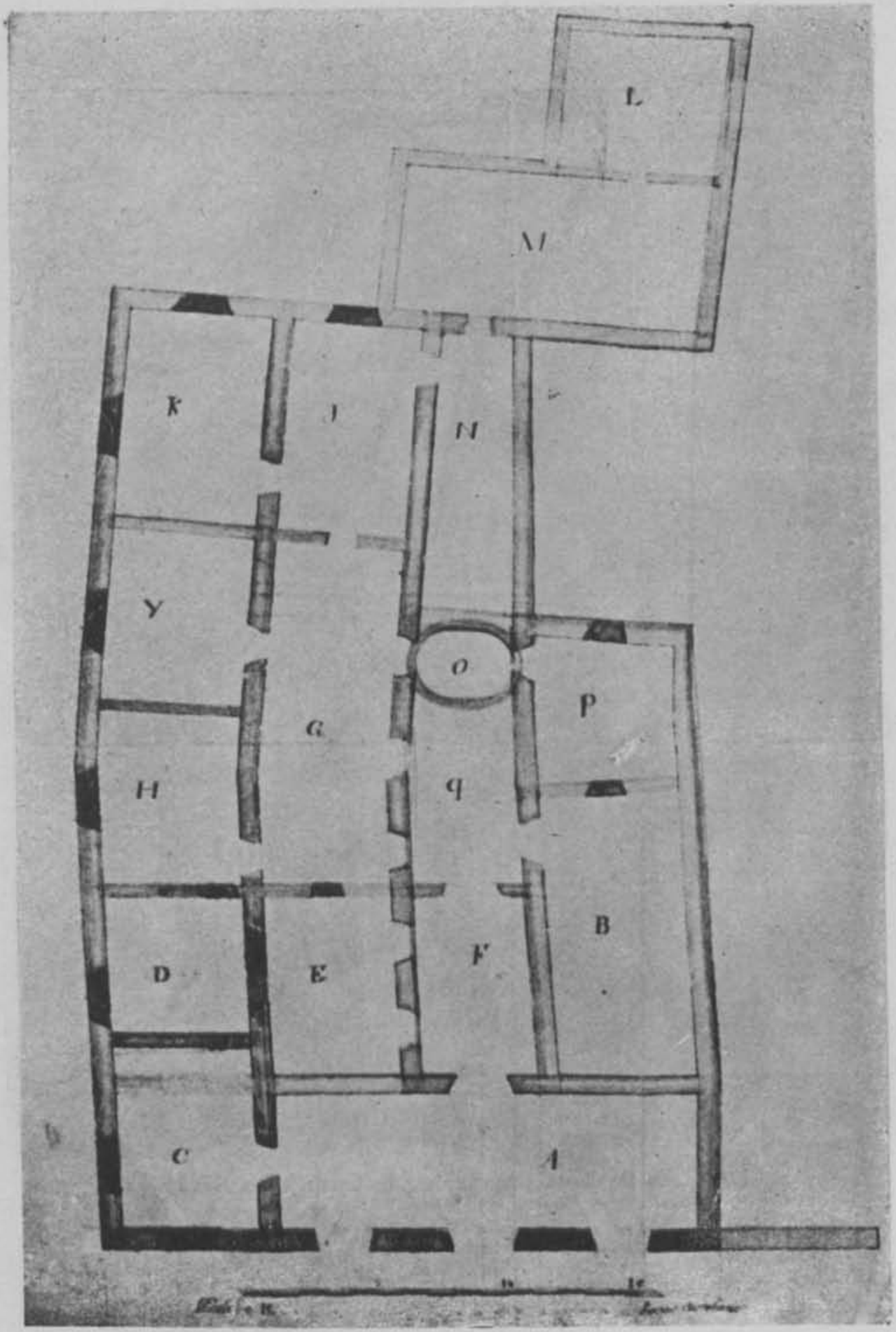

2. Plano de las Casas Reales de Guanajuato. 1792. 
DOI: http://dx.doi.org/10.22201/iie.18703062e.1953.21.553

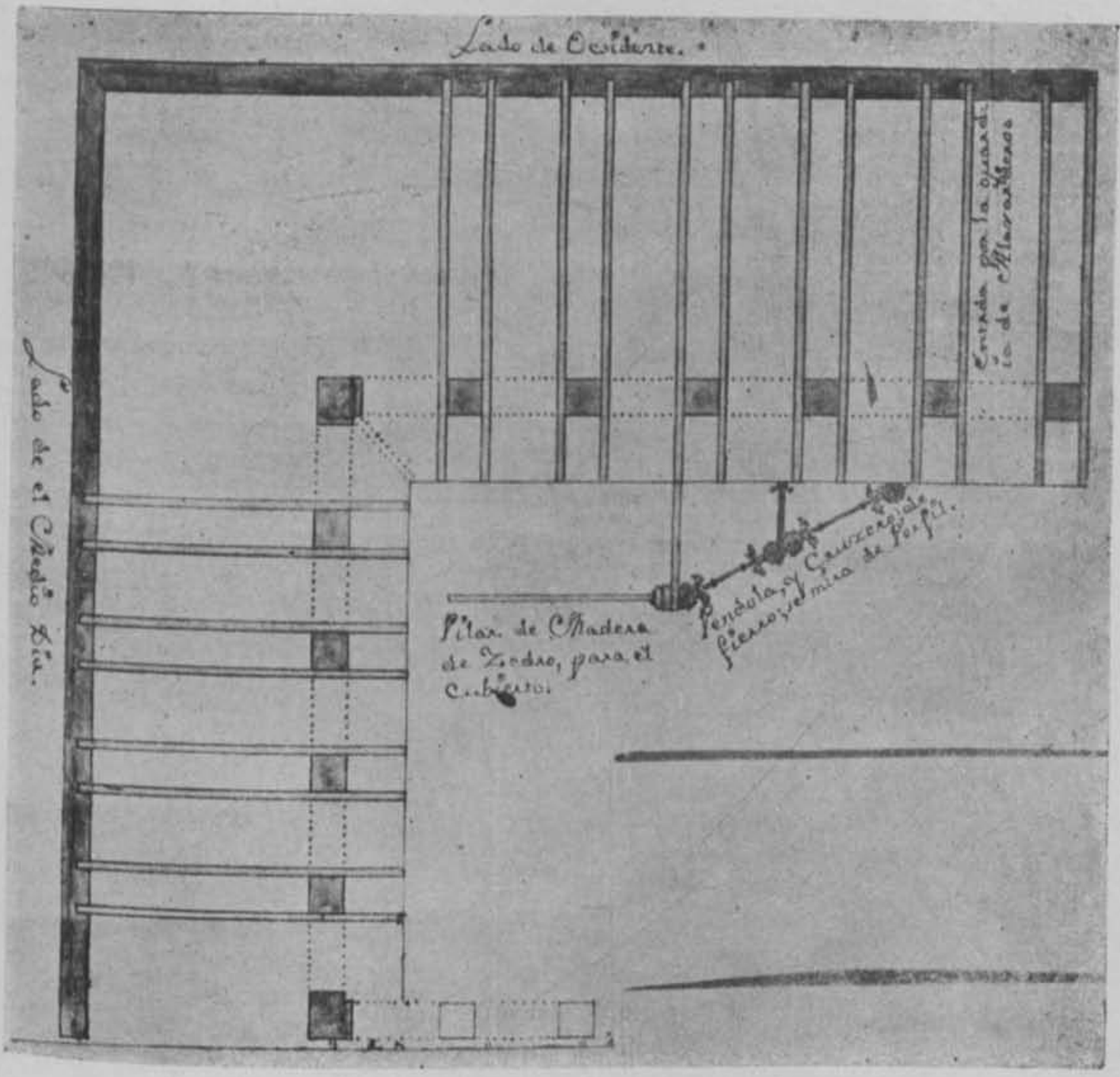

3. Planta alta de un corredor del Palacio Real de México, 1761. 
DOI: http://dx.doi.org/10.22201/iie.18703062e.1953.21.553

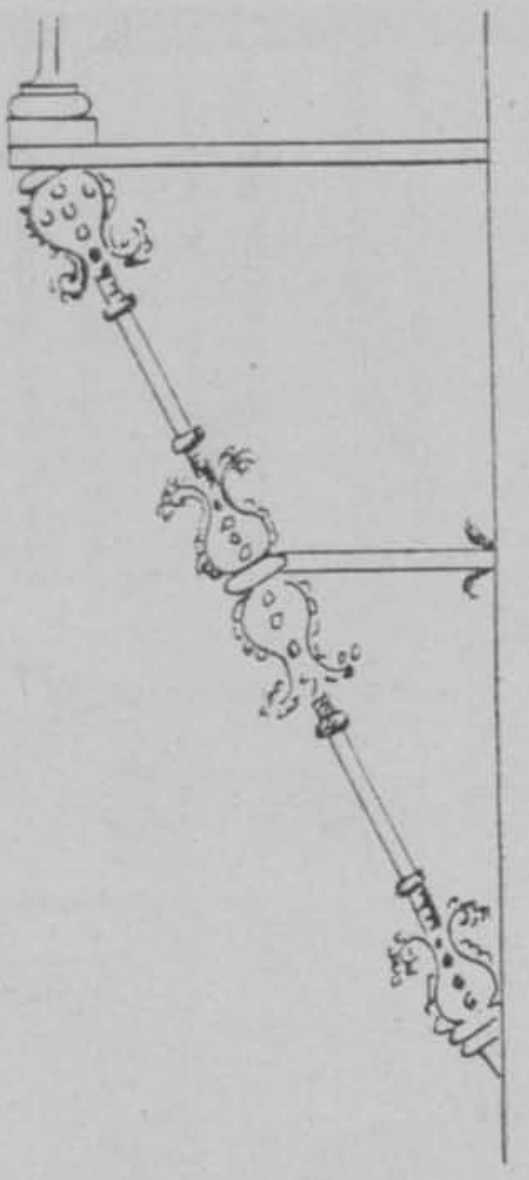

4. Soporte de hierro del balcón. (Dibujo de Oscar Frias.) 
DOI: http://dx.doi.org/10.22201/iie.18703062e.1953.21.553

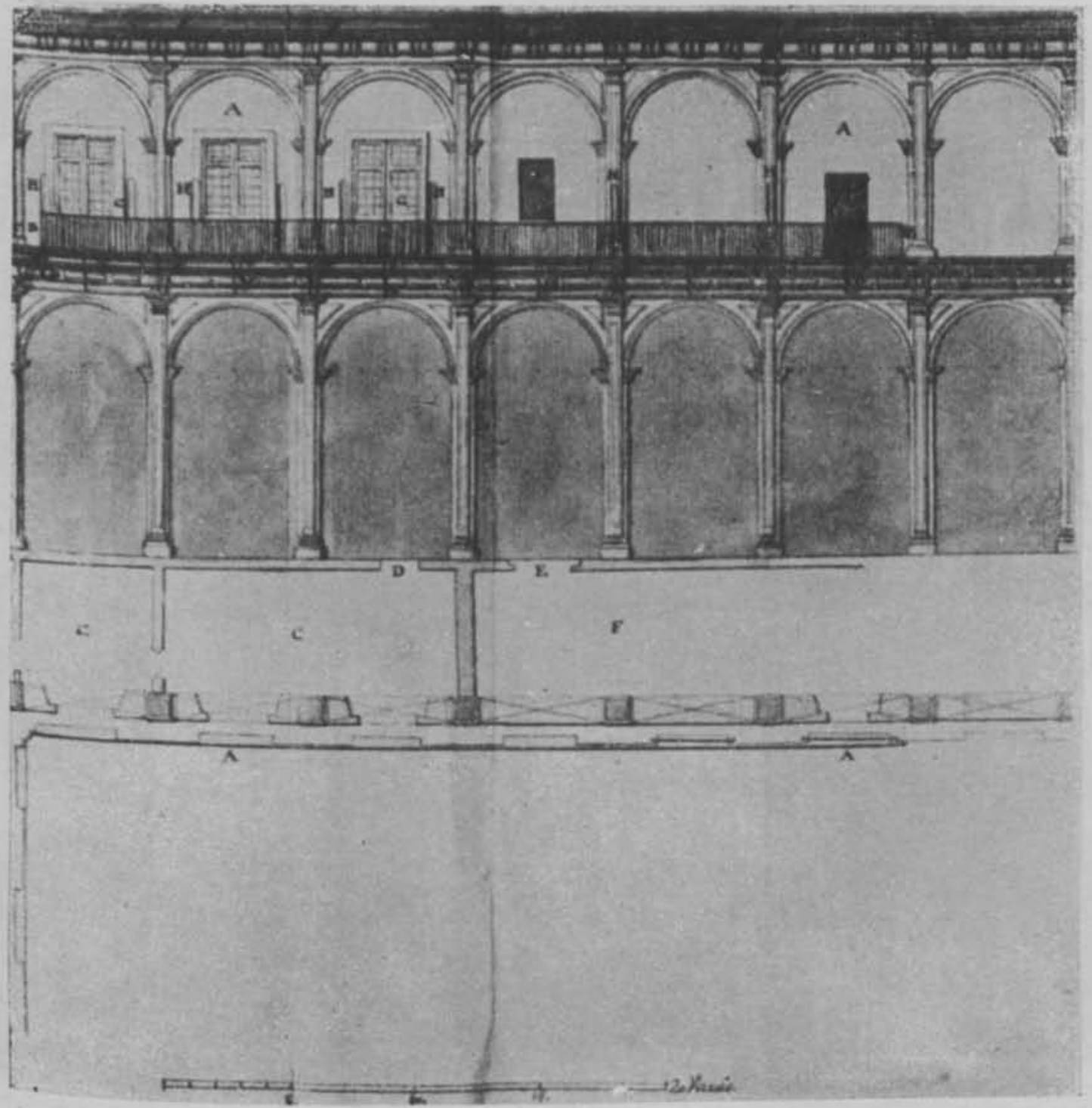

5. Alzado general del corredor del Palaciu Real de México. 
DOI: http://dx.doi.org/10.22201/iie.18703062e.1953.21.553

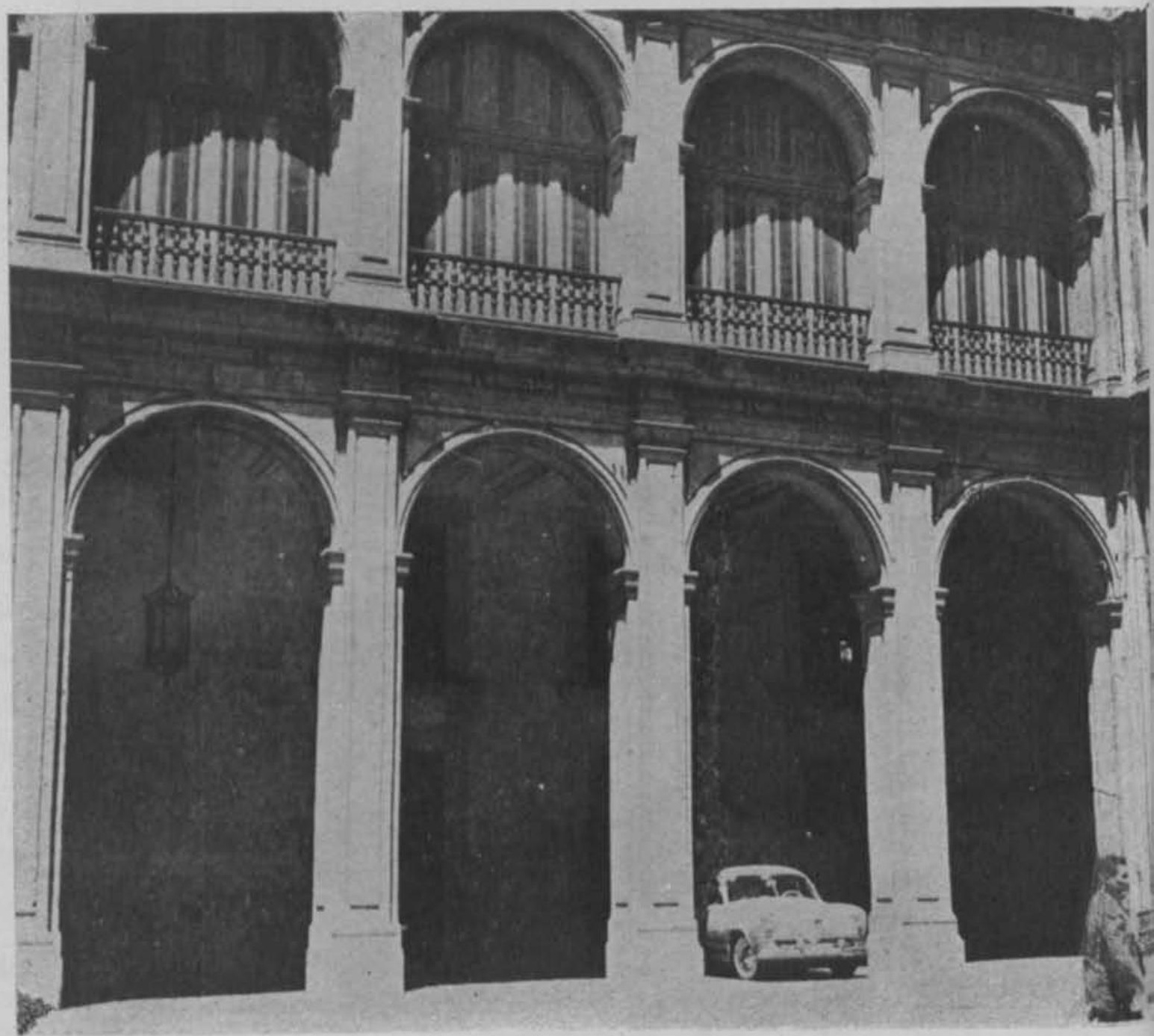

6. Patio del Palacio Real de México (hoy Palacio Nacional). Estado actual. 
DOI: http://dx.doi.org/10.22201/iie.18703062e.1953.21.553

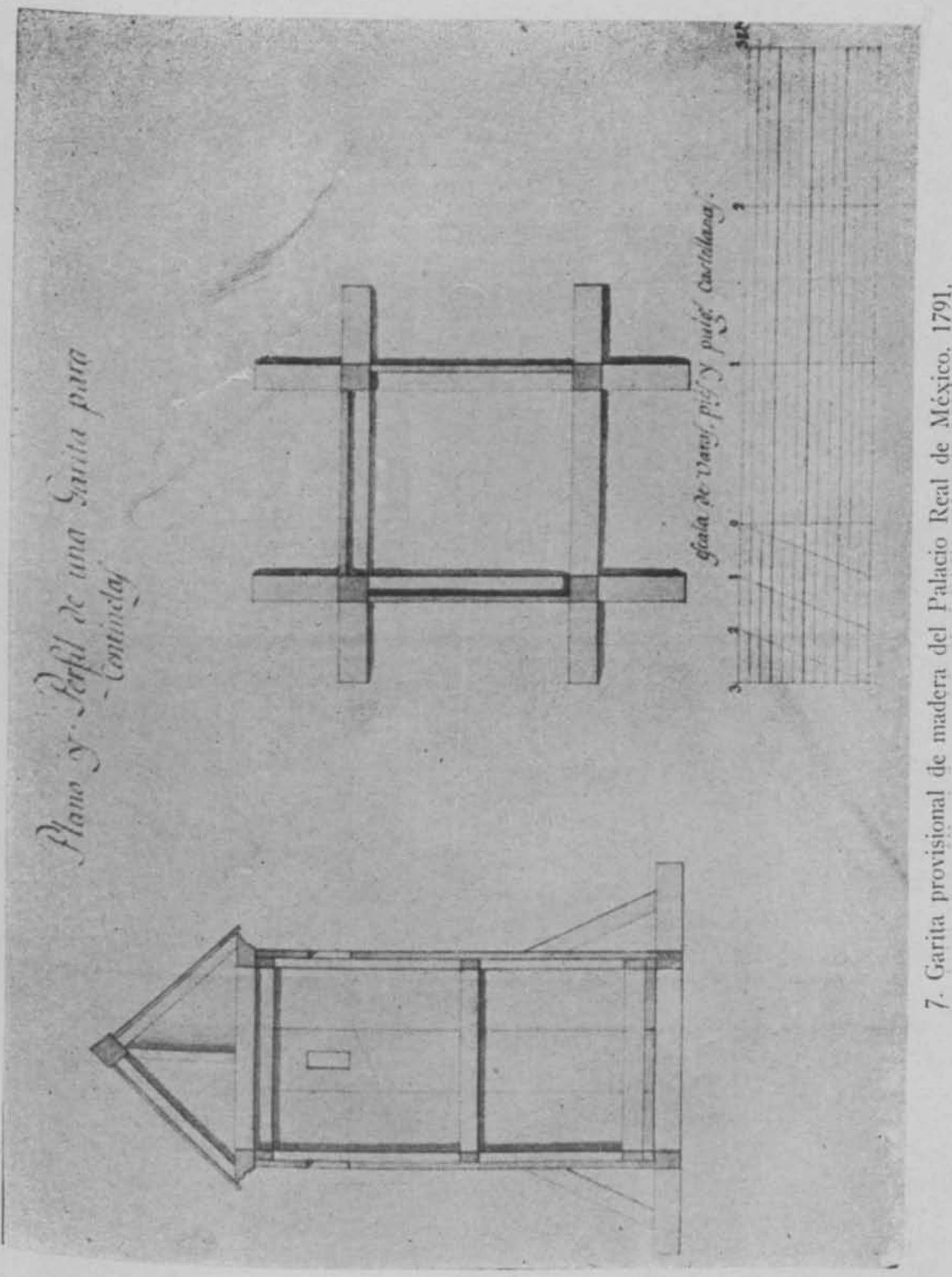


DOI: http://dx.doi.org/10.22201/iie.18703062e.1953.21.553

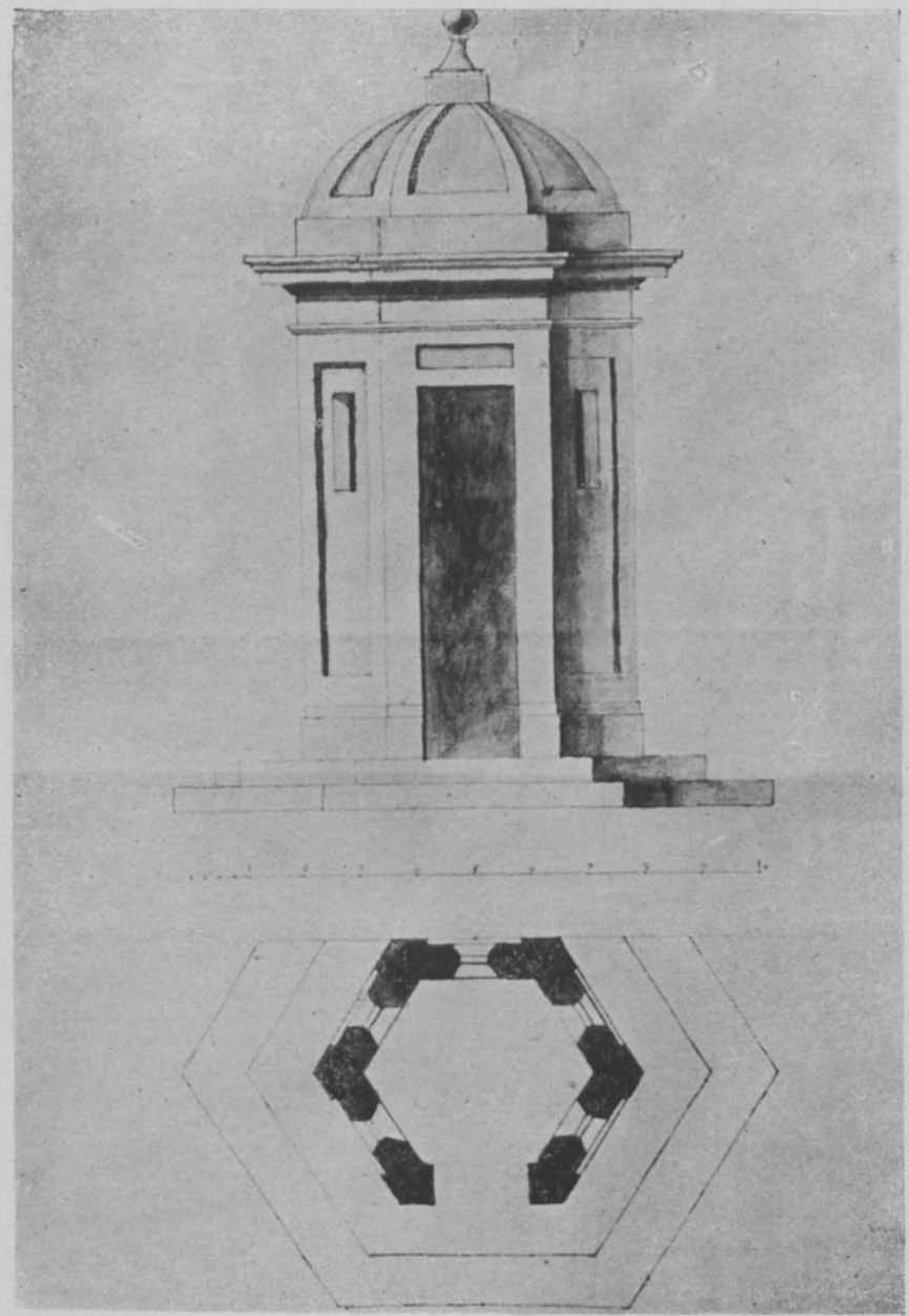

8. Garita de piedra del Palacio Real de México. 1792. 